\title{
Evaluation of simple International ovarian tumor analysis ultra sound rules in differentiating between benign and malignant ovarian tumors and their histopathological correlation
}

\author{
Bhawna Sharma $^{1 *}$, Neetu Arora1, Rajiv Acharya ${ }^{1}$, Vineeta Gupta1, Anshu Sharma1, \\ Namrata Saxena ${ }^{1}$, Brijesh Thakur ${ }^{2}$, Rohit Sharma ${ }^{3}$
}

\begin{abstract}
${ }^{1}$ Department of Obstetrics and Gynecology, Shri Guru Ram Rai Institute of Medical and Health Sciences, Dehradun, Uttarakhand, India

${ }^{2}$ Department of Pathology, Shri Guru Ram Rai Institute of Medical and Health Sciences, Dehradun, Uttarakhand, India ${ }^{3}$ Department of Radiology, Shri Guru Ram Rai Institute of Medical and Health Sciences, Dehradun, Uttarakhand, India
\end{abstract}

Received: 23 November 2019

Revised: 24 December 2019

Accepted: 31 December 2019

\section{*Correspondence:}

Dr. Bhawna Sharma,

E-mail: bsbhawna@gmail.com

Copyright: (C) the author(s), publisher and licensee Medip Academy. This is an open-access article distributed under the terms of the Creative Commons Attribution Non-Commercial License, which permits unrestricted non-commercial use, distribution, and reproduction in any medium, provided the original work is properly cited.

\section{ABSTRACT}

Background: IOTA (International ovarian tumor analysis) study is considered one of the largest studies on ultrasound diagnosis of ovarian pathology conducted in literature till date. It was started in 1999 and included nine European countries. It is a standardized technique for preoperative classification of ovarian pathology defined by IOTA group.

Methods: A retrospective study was analyzed from a period of January 2016 to December 2017 (2-year period). The records of all the patients operated for benign and malignant ovarian pathology in the gynae department of hospital were retrieved from medical record sections. USG findings were redefined as per IOTA simple rules by sonologist and its histopathological correlation was done using kappa statistical method.

Results: In the present study, out of 61 patients IOTA was applicable to 57 patients. The sensitivity where IOTA simple rules were applicable was $92.8 \%$ and the specificity was $93 \%$. The accuracy turned out to be $92.9 \%$. If inconclusive results were taken as malignant then sensitivity increased to $94 \%$ and specificity decreased to $87 \%$. Good level of agreement was found between sonological and histopathological findings with Kappa statistics application $(\mathrm{K}=0.59)$.

Conclusions: The IOTA simple rules can be considered as an important diagnostic modality in differentiation of benign and malignant ovarian tumors, it has an added advantage of abolishing the subjectivity of routine ultrasound. However inconclusive results demand further expertise in the field and need to be taken care of before interpretation of ovarian pathologies.

Keywords: B-Rules, International ovarian tumor analysis, Kappa statistics, M-Rules, Ovarian pathology, Ultrasound

\section{INTRODUCTION}

Distinguishing ovarian pathologies as benign or malignant preoperatively is of paramount importance as the therapeutic approach of management of each kind is entirely different. One such approach for distinction is IOTA (International ovarian tumor analysis). The study on IOTA is considered as one of the largest study conducted on ultrasound diagnosis till date. It was started in 1999 and included nine European countries. It is a 
standardized technique for preoperative classification of ovarian pathology defined by IOTA group. The rules are based on simple demonstration of certain sonographic findings, some of which are indicative of malignancy (Mrules) and others of benign behaviour (B-rules) and if neither is applicable, the mass could not be classified and was labelled inconclusive (Table 1).

Table 1: Simple IOTA rules for predicting benign or malignant ovarian tumor.

\begin{tabular}{|ll|}
\hline $\begin{array}{l}\text { Rules for predicting a } \\
\text { malignant tumor } \\
\text { (M -rules) }\end{array}$ & $\begin{array}{l}\text { Rules for predicting a } \\
\text { benign tumor } \\
\text { (B - rules) }\end{array}$ \\
\hline $\begin{array}{l}\text { M1 - Irregular solid } \\
\text { tumor }\end{array}$ & B1 - Unilocular cyst \\
\hline B2 - Presence of ascites & $\begin{array}{l}\text { component where largest } \\
\text { solid component is less } \\
\text { than 7mm in largest } \\
\text { diameter }\end{array}$ \\
\hline $\begin{array}{l}\text { M3 - AT least 4 papillary } \\
\text { structure }\end{array}$ & $\begin{array}{l}\text { B3 - Presence of acoustic } \\
\text { shadows }\end{array}$ \\
\hline $\begin{array}{l}\text { M4 - Irregular } \\
\text { multilocular solid tumor } \\
\text { with largest diameter } \\
\text { greater 100 mm }\end{array}$ & $\begin{array}{l}\text { B4 - Smooth multilocula } \\
\text { tumor with largest } \\
\text { diameter less than 100 } \\
\text { mm }\end{array}$ \\
\hline $\begin{array}{l}\text { M5 - Very strong blood } \\
\text { flow (color score 4) }\end{array}$ & $\begin{array}{l}\text { B5 - No blood loss (color } \\
\text { score 1) }\end{array}$ \\
\hline
\end{tabular}

It is well known that the five-year survival rate associated with ovarian cancer is less than $30 \%$. One of the contributing factors of such a low survival rate is lack of reproducibility of standardized terms and procedures in gynecological sonography. The use of IOTA simple ultrasound rules may eliminate this issue being highly sensitive and specific in predicting ovarian malignancy. The observation according to IOTA is reproducible, easy to train for and can be used with ease. ${ }^{1}$ In literature there are tremendous studies conducted on the applicability of IOTA rules on distinguishing the benign and malignant behaviour, however there is lack of prospective studies carried in this regard.

This study was conducted to truly establish the diagnostic performance of these rules and to estimate and correlate the sensitivity and specificity of given rules with histopathological diagnosis and establish their use as a tool in early diagnosis of ovarian malignancy.

\section{METHODS}

A retrospective study was conducted from a period of January 2016 to December 2017 (2-year period).

\section{Inclusion criteria}

- All the patients who had been operated for suspected ovarian pathology (benign or malignant) in the hospital in the above-mentioned period were included in the study.

\section{Exclusion criteria}

- All the patients where tubal pathology is also suspected in addition to ovarian pathology like tubo ovarian mass because of pelvic inflammatory disease or tuberculosis

- Patients with suspected chronic ectopic masses

- Para ovarian cysts.

Study population constitutes all the patients included in the study.

The medical records of the patients included in the study were retrieved from medical record section. The ultrasound findings of all the cases attached with their respective medical files were summarized according to IOTA simple ultrasound rules, were divided into benign, malignant, and inconclusive categories by sonologist and were matched with histopathological reports and then the sonological and histopathological correlation was established using kappa statistics to establish the usefulness of IOTA simple rules.

\section{RESULTS}

In the present study total 61 patients were included, the youngest was 16 years old and eldest was 68. The mean age was 42.5 years. In our study we found that malignancy was more common in elderly $\left(6^{\text {th }}\right.$ decade $)$ and postmenopausal women (Table 2) and (Table 3) where the figures are maximum 53.33 and 66.6 percent respectively. Out of 61 patients IOTA rules were applicable to 57 patients, in rest of the 5 patients' rules were not applicable and were termed as inconclusive. Among 57 applicable patients 41 were indicative of benign and 16 of malignant (Table 4).

Table 2: Age distribution in benign and malignant ovarian masses $(n=61)$.

\begin{tabular}{|lllll|}
\hline $\begin{array}{l}\text { Age } \\
\text { group (in } \\
\text { years) }\end{array}$ & Benign & \multicolumn{3}{c|}{ Malignant } \\
\hline & Number & $\%$ & Number & $\mathbf{\%}$ \\
\hline 11-25 years 7 & $15.21 \%$ & 0 & $0 \%$ \\
\hline 26-40 years & 32 & $69.56 \%$ & 3 & $20 \%$ \\
\hline 41-55 years & 3 & $6.5 \%$ & 2 & $13.33 \%$ \\
\hline 56-70 years & 3 & $6.5 \%$ & 8 & $53.33 \%$ \\
\hline 71-85 years & 1 & $0.02 \%$ & 1 & $6.66 \%$ \\
\hline Total & $\mathbf{4 6}$ & $\mathbf{1 0 0 \%}$ & $\mathbf{1 5}$ & $\mathbf{1 0 0 \%}$ \\
\hline
\end{tabular}

In the present study 18 different combinations of benign and malignant simple ultrasound features were encountered (Table 5). Out of 18 combinations most common was B1 and B3 combination frequency of which was 9. Out of these 9 patients one had final 
histopathological diagnosis of malignancy, so the rate of malignancy in this particular combination was $11.1 \%$. Out of 4 combinations of $100 \%$ rate of malignancy, most frequent combination was application of rule M2, M3 and M5, having frequency of five.

Table 3: Relation of menopausal status with ovarian tumors.

\begin{tabular}{|lllll|}
\hline Menopausal status & Benign & $\%$ & Malignant & $\%$ \\
\hline Postmenopausal & 6 & $13 \%$ & 10 & $66.66 \%$ \\
\hline Premenopausal & 40 & $86.9 \%$ & 5 & $33.33 \%$ \\
\hline Total & $\mathbf{4 6}$ & $\mathbf{1 0 0 \%}$ & $\mathbf{1 5}$ & $\mathbf{1 0 0 \%}$ \\
\hline
\end{tabular}

Table 4: Classification of cases as per IOTA simple ultrasound rules.

\begin{tabular}{|ll|}
\hline Nature of the mass as per ITOA rules & No \\
\hline Benign & 41 \\
\hline Malignant & 16 \\
\hline Indeterminate & 4 \\
\hline Total & $\mathbf{6 1}$ \\
\hline
\end{tabular}

Out of all benign factors, B1 is the most common occurring factor, however B2, B4 and B5 predicted the result most correctly (100\%) followed by B1 and B5 (Table 6).

Among $\mathrm{M}$ factors $\mathrm{M} 2$ was the most common factor but the predictability of M3 factor was maximum which correctly predicted malignancy in seven patients (Table 7).

Kappa statistics $(\mathrm{K}=0.59)$ (Table 8) shows good level of agreement between sonology and histopathological findings (> 0.75 - excellent, 0.4-0.75-good, < 0.4-poor).

Table 5: Observed combinations of benign and malignant ultrasound features of IOTA simple rules ranked by frequency.

\begin{tabular}{|c|c|c|c|c|c|c|c|c|c|c|c|c|c|c|}
\hline \multicolumn{6}{|c|}{ Applicable B factors } & \multicolumn{4}{|c|}{ Applicable $\mathbf{M}$ factors } & \multirow[b]{2}{*}{ M5 } & \multirow[b]{2}{*}{ FREQ } & \multirow[b]{2}{*}{ Benign } & \multirow[b]{2}{*}{ Malignant } & \multirow[b]{2}{*}{$\begin{array}{l}\text { Rate of } \\
\text { malignancy }\end{array}$} \\
\hline SN & B1 & B2 & B3 & B4 & B5 & M1 & M2 & M3 & M4 & & & & & \\
\hline 1 & 1 & 0 & 1 & 0 & 0 & 0 & 0 & 0 & 0 & 0 & 9 & 8 & 1 & $11.15 \%$ \\
\hline 2 & 1 & 0 & 0 & 0 & 1 & 0 & 0 & 0 & 0 & 0 & 8 & 8 & 0 & $0 \%$ \\
\hline 3 & 1 & 1 & 0 & 0 & 1 & 0 & 0 & 0 & 0 & 0 & 5 & 5 & 0 & $0 \%$ \\
\hline 4 & 0 & 0 & 0 & 0 & 1 & 0 & 0 & 0 & 0 & 0 & 6 & 6 & 0 & $0 \%$ \\
\hline 5 & 1 & 0 & 0 & 0 & 0 & 0 & 0 & 0 & 0 & 0 & 5 & 5 & 0 & $0 \%$ \\
\hline 6 & 1 & 0 & 1 & 0 & 1 & 0 & 0 & 0 & 0 & 0 & 2 & 2 & 0 & $0 \%$ \\
\hline 7 & 0 & 0 & 1 & 1 & 0 & 0 & 0 & 0 & 0 & 0 & 2 & 2 & 0 & $0 \%$ \\
\hline 8 & 1 & 0 & 0 & 0 & 0 & 0 & 0 & 0 & 0 & 0 & 3 & 3 & 0 & $0 \%$ \\
\hline 9 & 1 & 1 & 0 & 1 & 1 & 0 & 0 & 0 & 0 & 0 & 1 & 1 & 0 & $0 \%$ \\
\hline 10 & 0 & 0 & 0 & 0 & 0 & 0 & 1 & 1 & 0 & 1 & 5 & 0 & 5 & $100 \%$ \\
\hline 11 & 0 & 0 & 0 & 0 & 0 & 0 & 1 & 0 & 0 & 0 & 4 & 2 & 2 & $50 \%$ \\
\hline 12 & 0 & 0 & 0 & 0 & 0 & 0 & 1 & 1 & 1 & 0 & 2 & 0 & 2 & $100 \%$ \\
\hline 13 & 0 & 0 & 0 & 0 & 0 & 1 & 1 & 0 & 0 & 0 & 3 & 1 & 2 & $66.6 \%$ \\
\hline 14 & 0 & 0 & 0 & 0 & 0 & 1 & 1 & 0 & 0 & 0 & 2 & 0 & 2 & $100 \%$ \\
\hline 15 & 0 & 1 & 0 & 0 & 0 & 0 & 1 & 0 & 0 & 0 & 1 & 1 & 0 & $0 \%$ \\
\hline 16 & 0 & 0 & 1 & 0 & 0 & 0 & 0 & 0 & 1 & 1 & 1 & 1 & 0 & $0 \%$ \\
\hline 17 & 0 & 1 & 0 & 0 & 0 & 0 & 1 & 0 & 0 & 0 & 1 & 1 & 0 & $0 \%$ \\
\hline 18 & 0 & 0 & 1 & 0 & 0 & 0 & 0 & 0 & 1 & 1 & 1 & 0 & 1 & $100 \%$ \\
\hline
\end{tabular}

In our study the sensitivity of IOTA simple rules for the detection of malignancy where applicable was $92.8 \%$, whereas specificity was $93 \%$, it had the positive predictive value of $81.2 \%$, with a comparatively high negative predictive value of $97.5 \%$ and the accuracy of $92.9 \%$ (Table 9). There was one false negative case in our study where there were presence of acoustic shadows and 
later on it turned out to be serous epithelial ovarian cancer in histopathological diagnosis.

Table 6: Prevalence and predictive power of benign factors.

\begin{tabular}{|llll|}
\hline Benign & Predicted & Result & Percentage \\
\hline B1 & 33 & 32 & $96.96 \%$ \\
\hline B2 & 11 & 11 & $100 \%$ \\
\hline B3 & 15 & 13 & $86.66 \%$ \\
\hline B4 & 3 & 3 & $100 \%$ \\
\hline B5 & 22 & 22 & $100 \%$ \\
\hline
\end{tabular}

Table 7: Prevalence and predictive power of malignant factor.

\begin{tabular}{|llll|}
\hline Malignant & Predicted & Result & Percentage \\
\hline M1 & 5 & 4 & $80 \%$ \\
\hline M2 & 18 & 13 & $72.22 \%$ \\
\hline M3 & 7 & 7 & $100 \%$ \\
\hline M4 & 3 & 2 & $66.66 \%$ \\
\hline M5 & 6 & 5 & $83.33 \%$ \\
\hline
\end{tabular}

Table 8: Comparison of results of IOTA simple rules with histopathological findings.

\begin{tabular}{|llll|}
\hline $\begin{array}{l}\text { Nature of the mass } \\
\text { as per iota rules }\end{array}$ & No & Benign & Malignant \\
\hline Benign & 4 & 40 & 1 \\
\hline Malignant & 16 & 3 & 13 \\
\hline Indeterminate & 4 & 4 & 1 \\
\hline
\end{tabular}

Table 10 depicts the comparison between the sonographic and histopathological diagnosis of inconclusive cases.

Table 9: Efficacy of IOTA simple rules.

\begin{tabular}{|ll|}
\hline \multicolumn{2}{|l|}{ Efficacy of IOTA simple rules } \\
\hline Sensitivity & $92.8 \%$ \\
\hline Specificity & $93 \%$ \\
\hline PPV & $81.2 \%$ \\
\hline NPV & $97.5 \%$ \\
\hline Accuracy & $92.9 \%$ \\
\hline
\end{tabular}

Table 10: Comparison between sonographic and histopathological findings of inconclusive cases.

\begin{tabular}{|ll|}
\hline $\begin{array}{l}\text { Sonographic findings } \\
\text { (IOTA rules) }\end{array}$ & Histopathology \\
\hline M2+ B2 & Mucinous cystadenoma \\
\hline B3+M4+M5 & Serous cystadenoma \\
\hline B2+M2 & Endometrioma \\
\hline B3+M4 & Immature teratoma \\
\hline
\end{tabular}

In addition to it, the study group had been divided into premenopausal and postmenopausal group and the results were depicted as in Table 11. The sensitivity was higher in postmenopausal $(91 \%)$ as compare to premenopausal $(83.3 \%)$ while specificity was lower $(88 \%$ and $97.5 \%$ respectively) (Table 12). If inconclusive results are considered as malignant sensitivity index increased from $92.8 \%$ to $94 \%$ and specificity decreased from $93 \%$ to $87 \%$ respectively (Table 13 ).

Table 11: Comparison of results of present study with the published data is shown.

\begin{tabular}{|c|c|c|c|c|c|c|c|c|c|c|c|}
\hline 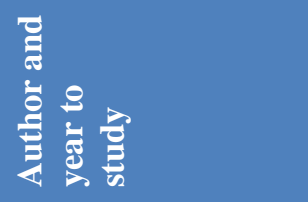 & 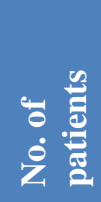 & 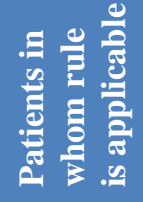 & 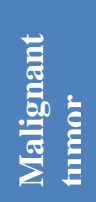 & 离 & 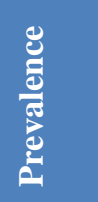 & 욜 & $\frac{0}{\frac{0}{6}}$ & 龸 & 일 & 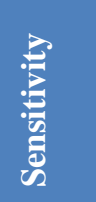 & 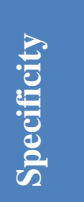 \\
\hline Timmerman $\mathrm{D}$ et $\mathrm{al}^{10}$ & 507 & 386 & - & - & 29 & 106 & 25 & 6 & 249 & 95 & 91 \\
\hline Timmerman D et $\mathrm{al}^{8}$ & 1938 & 1501 & 542 & 1396 & 25 & 34 & 49 & 29 & 1083 & 92 & 96 \\
\hline Fathallah $\mathrm{K}$ et $\mathrm{al}^{9}$ & 122 & 109 & 14 & 108 & 10.10 & 8 & 3 & 3 & 95 & 73 & 97 \\
\hline Hartman CA et $\mathrm{al}^{11}$ & 103 & 91 & 30 & 73 & 24.20 & 20 & 9 & 2 & 60 & 91 & 87 \\
\hline Sayasneh A et al ${ }^{12}$ & 255 & 214 & 74 & 181 & 24.80 & 46 & 3 & 7 & 158 & 87 & 98 \\
\hline Alcazar JL et al ${ }^{13}$ & 340 & 270 & 55 & 285 & 12.20 & 29 & 6 & 4 & 231 & 88 & 97 \\
\hline Nunes $\mathrm{N}$ et $\mathrm{al}^{14}$ & 303 & 237 & 135 & 168 & 44.30 & 101 & 15 & 4 & 117 & 96 & 89 \\
\hline Garg et $\mathrm{al}^{15}$ & 50 & 45 & 14 & 36 & 28.00 & 11 & 5 & 1 & 28 & 91.66 & 84.84 \\
\hline Present study & 61 & 57 & 15 & 46 & 24.6 & 13 & 3 & 1 & 40 & 92.8 & 93 \\
\hline
\end{tabular}

\section{DISCUSSION}

The differentiation of benign and malignant tumors is based on several diagnostic modalities such as clinical assessment, CA125, (Erdogan et al; Mousavi et al), sonographic morphology (Sassone et al; Timmerman et al) or doppler evaluation (Kurjak et al; Tongsong et al). ${ }^{2-7}$ However the most proposed sonographic assessment requires higher degree of expertise, limiting their wider use in clinical practice. To overcome this factor Timmerman et al, elicited IOTA simple rules and 
validated it for diagnostic performance. ${ }^{8}$ The simple rules seem to be more attractive and practical because they are uncomplicated and user-friendly in categorizing an adnexal mass as benign or malignant. Nevertheless, only few studies from other groups in the world have been conducted to test the accuracy and reproducibility of the simple rules.

The present study is a retrospective one, where the sonographic data is collected from the record section and evaluated by the sonologist according to the prediction model and later on its histopathological correlation was done. 61 patients were included in the study, out of which IOTA rules were applicable to $57(93.4 \%)$ patients. Rest of the 5 patients were termed as inconclusive as they were not applicable. Among 57 applicable patients 41 $(67.2 \%)$ were suggested as benign and $16(26.2 \%)$ as malignant. Whereas Fathallah et al, performed a prospective study using the IOTA simple rules in a series of 122 masses. $^{9}$ The malignancy rate was $11.5 \%$ (14 malignancies). The IOTA simple rules were applicable in $89.3 \%$ of masses.

Table 12: Comparative sensitivity and specificity of published data with the current study in pre and postmenopausal women. ${ }^{3,5-8}$

\begin{tabular}{|c|c|c|c|c|}
\hline Author and year of study & $\begin{array}{l}\text { Patients with } \\
\text { rules applicable }\end{array}$ & Prevalence of malignancy & Sensitivity & Specificity \\
\hline \multicolumn{5}{|l|}{ All women } \\
\hline Timmerman $\mathrm{D}$ et $\mathrm{al}^{8}$ & 796 & 22.2 & 96 & 96 \\
\hline Hartman $\mathrm{CA}$ et $\mathrm{al}^{11}$ & 91 & 24.2 & 87 & 87 \\
\hline Sayasneh A et al ${ }^{12}$ & 214 & 24.8 & 98 & 98 \\
\hline Alcazar JL et al ${ }^{13}$ & 270 & 12.2 & 97 & 97 \\
\hline Nunes $\mathrm{N}$ et al ${ }^{14}$ & 237 & 44.3 & 89 & 89 \\
\hline Garg et al $^{15}$ & 45 & 28 & 91.66 & 84.84 \\
\hline Present study & 57 & 24.6 & 92.8 & 93 \\
\hline \multicolumn{5}{|l|}{ Premenopausal } \\
\hline Timmerman D et $\mathrm{al}^{8}$ & 526 & 9.5 & 90 & 97 \\
\hline Hartman CA et al ${ }^{11}$ & 39 & 23.1 & 89 & 90 \\
\hline Sayasneh A et al ${ }^{12}$ & 143 & 15.4 & 82 & 100 \\
\hline Alcazar JL et al ${ }^{13}$ & 217 & 7.4 & 88 & 97 \\
\hline Nunes $\mathrm{N}$ et al ${ }^{14}$ & 130 & 22.3 & 90 & 89 \\
\hline Garg et al ${ }^{15}$ & 30 & 3.33 & 100 & 86.2 \\
\hline Present study & 43 & 11 & 83.3 & 97.5 \\
\hline \multicolumn{5}{|l|}{ Postmenopausal } \\
\hline Timmerman D et $\mathrm{al}^{8}$ & 270 & 47 & 91 & 94 \\
\hline Hartman CA et al ${ }^{11}$ & 36 & 30.6 & 91 & 80 \\
\hline Sayasneh A et al ${ }^{12}$ & 71 & 43.7 & 90 & 93 \\
\hline Alcazar JL et al ${ }^{13}$ & 53 & 32.1 & 88 & 100 \\
\hline Nunes $\mathrm{N}$ et al ${ }^{14}$ & 107 & 71 & 99 & 87 \\
\hline Garg et al ${ }^{15}$ & 15 & 73.33 & 90.9 & 75 \\
\hline Present study & 14 & 72 & 91 & 88 \\
\hline
\end{tabular}

Table 13: Test performance of different simple rules (SR) strategies in the IOTA studies.

\begin{tabular}{|c|c|c|c|c|}
\hline Study & $\begin{array}{l}\text { Sensitivity if SR } \\
\text { applicable }\end{array}$ & $\begin{array}{l}\text { Specificity if SR } \\
\text { applicable }\end{array}$ & $\begin{array}{l}\text { Sensitivity With } \\
\text { SR+MA }\end{array}$ & $\begin{array}{l}\text { Specificity with } \\
\text { SR+MR }\end{array}$ \\
\hline Timmerman $\mathrm{D}$ et $\mathrm{al}^{8}$ & 91 & 96 & 94 & 80 \\
\hline Fathallah K et al $^{9}$ & 73 & 97 & 79 & 88 \\
\hline hartman CA et $\mathrm{al}^{11}$ & 91 & 87 & 94 & 76 \\
\hline Alcazar JL et al ${ }^{13}$ & 88 & 97 & 93 & 81 \\
\hline Nunes $\mathrm{N}$ et al ${ }^{14}$ & 96 & 89 & 97 & 70 \\
\hline Tantipalakorn $\mathrm{C}$ et $\mathrm{al}^{16}$ & 83 & 95 & 87 & 81 \\
\hline Garg et al $1^{15}$ & 92 & 85 & 93 & 80 \\
\hline Present study & 92.8 & 93 & 94 & 87 \\
\hline
\end{tabular}

SR-simple rules; SR+MA- simple rules+ inconclusive result considered as malignant. 
In our study the sensitivity of IOTA simple rules for the detection of malignancy where applicable was $92.8 \%$, whereas specificity was $93 \%$, it had the positive predictive value of $81.2 \%$, with a comparatively high negative predictive value of $97.5 \%$ and the accuracy of $92.9 \%$. The sensitivity and specificity of our study is comparable to the study of Timmerman et al (92\% and 96\% respectively) where as Fatallah et al has decreased sensitivity $(73 \%)$ and increased specificity $(97 \%)$ as compare to our study. ${ }^{8,9}$ On contrary Timmerman et al, has increased sensitivity and decreased specificity as compare to our study ( $95 \%$ and $91 \%$ respectively), the comparison of sensitivity and specificity of our study with various studies in literature is depicted on Table $9 .{ }^{10}$

Furthermore, the study group had been divided into premenopausal and postmenopausal and the results were reflected as in Table 11. It depicted that the sensitivity was higher in postmenopausal $(91 \%)$ as compare to premenopausal $(83.3 \%)$ while specificity was lower $(88 \%$ and $97.5 \%$ respectively). In the study of Hartman et al the sensitivity is lower in in premenopausal group (89\%) as compare to postmenopausal group (91\%) and specificity is higher In premenopausal (90\%) as compare to postmenopausal group $(80 \%) .{ }^{11}$ where as in the study of Sayashneh et al, the sensitivity and specificity are $82 \%$ and $100 \%$ respectively in premenopausal group where as in post-menopausal group the sensitivity and specificity are $90 \%$ and $93 \%$ respectively. The rate of inconclusive results was 4 out of 61 patients $(7.14 \%)$. Using a strategy classifying the inconclusive cases as malignant was adopted by many other authors in their respective studies as depicted in Table 13. ${ }^{12,13}$

If inconclusive results are considered as malignant sensitivity index increased from $92.8 \%$ to $94 \%$ and specificity decreased from $93 \%$ to $87 \%$ respectively. The result well correlated with the study of Timmerman D et al, Alcazar et al, Nunes et al, Garg et al and Tantipalakorn C et al. ${ }^{8,13-16}$

\section{CONCLUSION}

The most important prognosticating factor in any malignancy is its diagnosis well in time. With early and timely detection, the survival rates of patient improve effectively. USG offers inherent benefits of easy availability and low cost. Furthermore, it has an additional advantage of lack of radiation exposure; nevertheless, the problem often faced with USG is it is more subjective as compare to other diagnostic modalities. IOTA simple ultrasound rules can abolish this issue, as they are highly sensitive and specific in predicting ovarian malignancy yet being reproducible, easy to train and use. In conclusion, the IOTA simple rules have high diagnostic accuracy in differentiating between benign and malignant adnexal masses. Application of the IOTA simple rules yielded acceptable results in terms of sensitivity and specificity and its histopathological correlation proved to be effective statistically.

\section{Funding: No funding sources}

Conflict of interest: None declared

Ethical approval: The study was approved by the Institutional Ethics Committee

\section{REFERENCES}

1. Kaijser J, Bourne J, Valentin L, Sayasneh A, Van Holsbeke C, Vergote I, et al. Improving strategies for diagnosing ovarian cancer: a summary of the international ovarian tumour analysis (IOTA) studies. Ultrasound Obstet Gynaecol. 2013;41:9-20.

2. Erdogan N, Ozcelik B, Serin Is, Akgun M, Ozturk F. Doppler ultrasound assessment and serum cancer antigen 125 in the diagnosis of ovarian tumors. Int $\mathbf{J}$ Gynaecol Obstet. 2005;91:146-50.

3. Mousavi AS, Borna S, Moeinoddini S. Estimation of probability of malignancy using a logistic model combining color doppler ultrasonography, serum Ca125 level in women with a pelvic mass. Int $\mathbf{J}$ Gynecol Cancer. 2006;16:92-8.

4. Sassone AM, Timor-Tritsch IE, Artner A, Westhoff C, Warren WB. Transvaginal sonographic characterization of ovarian disease: evaluation of a new scoring system to predict ovarian malignancy. Obstet Gynecol. 1991;78:70-6.

5. Timmerman D, Schwarzler P, Collins WP. Subjective Assessment of Adnexal Masses with The Use Of Ultrasonography: An Analysis Of Interobserver Variability And Experience. Ultrasound Obstet Gynecol. 1999;13:11-6.

6. Kurjak A, Predanic M, Kupesic-Urek S, Jukic S. Transvaginal color and pulsed doppler assessment of adnexal tumor vascularity. Gynecol Oncol. 1993;50:3-9.

7. Tongsong $\mathrm{T}$, Wanapirak $\mathrm{C}$, Neeyalavira $\mathrm{V}$, Khunamornpong S, Sukpan K. E-Ow doppler indices for prediction of benign and malignant ovarian tumors. Asian Pac J Cancer Prev. 2009;10:139-42.

8. Timmerman D, Ameye L, Fischerova D. Simple ultrasound rules to distinguish between benign and malignant adnexal masses before surgery: prospective validation by IOTA Group. BMJ. 2010;341:6839.

9. Fathallah K, Huchon C, Bats AS. external validation of simple ultrasound rules of timmerman on 122 ovarian tumors. Gynecol Obstet Fertil. 2011;39:47781.

10. Timmerman D, Testa AC, Bourne T, Ameye L, Jurkovic D, Van Holsbeke C, et al. Simple ultrasound-based rules for the diagnosis of ovarian cancer. Ultrasound Obstet Gynaecol. 2008;31(6):681-90.

11. Hartman CA, Juliato CRT, Sarianlo, Toledo MC, Jales RM, Morais SS, et al. Ultrasound criteria and $\mathrm{Ca} 125$ as predictive variables of ovarian cancer in 
women with adnexal tumours. Ultrasound Obstet Gynaecol. 2012;40:360-6.

12. Sayasneh A, Kaijser J, Preisler J, Johnson S, Stalder C, Husicka R, et al. A multicenter prospective external validation of the diagnostic performance of iota simple descriptors and rules to characterise ovarian masses. Gynaecol Oncol. 2013;130(1):140-6.

13. Alcazar J, Pascual MA, Olartecoechea B, Graupera B, Auba M, Ajossa S, et al. IOTA simple rules for discriminating between benign and malignant adnexal masses: prospective external validation. Ultrasound Obstet Gynaecol. 2013;42:467-71.

14. Nunes N, Yazbek J, Ambler G, Hoo W, Naftalin J, Jurkovic D, et al. Prospective evaluation of the IOTA logistic regression model $\mathrm{Lr} 2$ for the diagnosis of ovarian cancer. Ultrasound Obstet Gynaecol. 2012;40(3):355-9.

15. Garg S, Kaur A, Mohi JK, Sibia PK, Kaur N. Evaluation of IOTA simple ultrasound rules to distinguish benign and malignant ovarian tumours. J Clin Diagnos Res. 2017;11(8):TC06.

16. Tantipalakorn $\mathrm{C}$, Wanapirak C, Khunamornpong S, Sukpan K, Tongsong T. IOTA simple rules in differentiating between benign and malignant ovarian tumours. Asian Paci C J Cancer Prevent. 2014;15(13):5123-16.

Cite this article as: Sharma B, Arora N, Acharya R, Gupta V, Sharma A, Saxena N, et al. Evaluation of simple International ovarian tumor analysis ultra sound rules in differentiating between benign and malignant ovarian tumors and their histopathological correlation. Int J Reprod Contracept Obstet Gynecol 2020;9:652-8. 